\title{
SOBRE LA PRODUCCIÓN LÍTICA EN ARQUEOLOGÍA
}

\author{
FRANCISCO JAVIER JOVER MAESTRE \\ Universidad de Alicante \\ javier.jover@ua.es
}

\begin{abstract}
Con el presente artículo, orientado dentro de la Arqueología Social, se realizan algunas aportaciones teóricas sobre los procesos de producción lítica y su análisis en arqueología. En concreto, se analiza la producción como proceso global -producción, distribución, intercambio y consumo-, la inferencia de la producción lítica y los procesos de clasificación utilizados.
\end{abstract}

In this article, about Social Archaeology, we make theorize about the lithic production processes and its analysis in archaeology. We center on production as a global process (production, distribution, change, consumption), the lithic production inference and the classification processes used.

\section{INTRODUCCIÓN}

Con el presente artículo, orientado dentro de la Arqueología Social, pretendemos realizar algunas aportaciones sobre el análisis de los procesos productivos en arqueología, centrándonos en la producción lítica, una de las actividades laborales más extendidas entre las poblaciones prehistóricas. Debido a ello, creemos necesario teorizar sobre la estrategia de gestión de la materia prima lítica con la que se manufacturaron una parte de los productos de consumo, tanto productivos como no productivos, imbricados dentro de las fuerzas productivas y que aportan información con la que aproximarnos a los modos de trabajo y modo de vida de las sociedades concretas históricas. El ejemplo manejado puede ser extrapolable al conjunto de los procesos productivos que se realizan en el seno de cualquier sociedad, siendo conscientes de que lo importante no es lo que se produce, sino más bien, cómo se produce.

\section{LA PRODUCCIÓN COMO PROCESO GLOBAL}

La producción, en términos generales, es un concepto teórico y constituye la forma específica a través de la cual se resuelven las necesidades de toda sociedad concreta. El conjunto de los procesos de producción, distribu- ción, cambio y consumo, así como su articulación en función de las relaciones sociales establecidas en el marco del trabajo, constituye el modo de producción.

Por nuestra parte, consideramos que la producción, la distribución, el intercambio y el consumo no pueden entenderse de forma separada, sino que forman parte del proceso general de producición. Como expuso MARX (1991: 49) "el resultado al que llegamos no es que la producción, la distribución, el cambio y el consumo sean idénticos, sino que constituyen las articulaciones de una totalidad, diferenciaciones dentro de una unidad".

La producción implica y supone necesariamente la apropiación y transformación de recursos naturales, en este caso concreto, determinados recursos litológicos, existentes en la naturaleza. Para ello las comunidades humanas pueden hacer uso de determinados instrumentos de trabajo de los que se valen para su obtención y manufactura, implicando producción e inmediatamente consumo. El consumo constituye el aspecto final de la producción, creando la necesidad de una nueva producción (MARX, 1991, 41). En palabras de MARX (1991, 41) "sin necesidad no hay producción. Pero el consumo reproduce la necesidad".

Una de las definiciones más completas sobre la producción es la aportada por BATE $(1996,43)$ quien considera que el proceso productivo "es el sistema orgánico de diversos procesos de trabajo concretos a través de los cua- 
les una sociedad genera diversos bienes que requiere para la satisfacción de las necesidades que permiten su mantenimiento y reproducción y que ésta es capaz de producir".

Es necesario insistir en el hecho de que en todo proceso productivo interviene obligadamente la fuerza de trabajo, los objetos de trabajo -materia prima- y los instrumentos de trabajo. El resultado de la interacción de estos elementos tiene como objetivo fundamental la producción de bienes de uso con los que cubrir las necesidades sociales y como consecuencia, la generación de desechos desde el mismo inicio de la producción.

Mientras la producción es social, realizada conforme a las relaciones que se establecen entre los seres humanos en el trabajo y tiende a cubrir las necesidades del conjunto del grupo humano, el consumo de los productos resultantes se convierte en objeto de disfrute, de apropiación individual. "En el consumo la cosa se subjetiviza" (MARX, 1991,39).

Se puede decir que el consumo constituye la negación de la producción, debido a que la producción de valores de uso adquieren su máxima expresión y sentido en el consumo, el cual, a su vez, se genera una nueva producción. MARX $(1991,43)$ distinguió entre dos tipos de consumo. El consumo productivo donde los productos se reintegran al proceso de trabajo como medios de trabajo -instrumentos de trabajo- y el no productivo donde los productos son consumidos directamente por los seres humanos en tanto que son utilizados para el mantenimiento y reproducción -también ideológica- de la fuerza de trabajo. Los productos líticos se pueden incluir en ambos tipos, aunque el volumen más destacado se corresponde con el primero de ellos.

Por ello, la organización de la distribución está determinada por la producción, no sólo debido a que únicamente se pueden distribuir los resultados de la producción, sino también a que el modo como se participa en la producción determina la forma bajo la que se interviene en la distribución (MARX, 1991, 45).

Pero entre la producción y la distribución podemos encontrar un momento mediador. como es el intercambio. Se trata de un proceso de redistribución que permite a los individuos de una sociedad obtener bienes de uso específicos requeridos por el consumo (BATE, 1996, 47). De este modo, al valor de uso se le añade el valor de cambio. La complejidad del intercambio depende del grado de desarrollo de la división social del trabajo en el seno de una sociedad, entendida ésta como la existencia de individuos o de grupos de especialistas cuya actividad laboral está destinada exclusivamente a la producción de una determinada clase de bienes, o incluso, de partes del proceso de trabajo de los mismos.

A la articulación en un mismo proceso de las diversas actividades laborales concretas destinadas a la producción de un mismo tipo de bienes la denominamos organización técnica del trabajo, y cuya organización diferencial de tareas constituye la división técnica del trabajo (BATE, 1996, 45).

Por lo tanto, el análisis de los productos de cualquier sociedad, con independencia de la materia prima sobre la que esté elaborada, debe realizarse teniendo en cuenta la unidad que constituye la producción, distribución, intercambio y consumo, además de cómo se organiza técnicamente el trabajo y si existe o no division social del mismo en la realización de los diferentes procesos productivos, observable en arqueología a través de las diferentes unidades básicas empleadas -artefactos, áreas de actividad, unidades de ocupación, asentamientos, territorios-.

\section{LA PRODUCCIÓN LÍTICA EN ARQUEOLOGÍA}

Con estos precedentes, en cualquier análisis que emprendamos nos interesa descubrir los procesos de producción, distribución, intercambio y consumo de las sociedades en estudio a través del estudio de los artefactos y de las diversas asociaciones y recurrencias documentadas en las unidades básicas de observación. En concreto, se trata de investigar la historia de los productos líticos en sus contextos arqueológicos, abarcando desde la forma de obtención, determinación del lugar de procedencia de las materias primas empleadas como soporte, hasta quiénes manufacturaron los productos, quiénes lo distribuyeron y lo consumieron, incluso el mismo abandono de los productos en los contextos arqueológicos, así como los diferentes procesos que le han afectado con posterioridad, una vez que es documentado por el arqueológo. Pero ello sólo lo podremos hacer cuando conozcamos los posibles desarrollos de los diferentes contextos donde participaron (RAMOS, 1988, 417).

En este sentido, para la elaboración de cualquier producto localizado en un contexto arqueológico fue necesaria la realización de 
toda una serie de trabajos, claramente articuladas en procesos sucesivos, paralelos o acumulativos, desarrollados en una secuencia temporal y espacial (MARTÍNEZ y AFONSO, 1994). Posteriormente, una vez que se deslindan de la actividad humana - vida cotidiana- y pasan a formar parte del contexto arqueológico, siguen modificándose sus condiciones por procesos sociales y naturales, incluso después de haber sido "capturados" por el arqueólogo.

A algunos de los procesos que supone la producción lítica dedicó sus esfuerzos LEROIGOURHAN (1971). Este autor introdujo la definición de cadena operativa retomándola del trabajo de los etnólogos que habían empezado a utilizarla en la década de los cincuenta, en un intento de definir las técnicas empleadas en sus distintos momentos secuenciales (DOMÉNECH, 1993, 31). No obstante, la utilización del término de cadenas operativas en su aplicación a la arqueología se formuló desde una posición teórica diferente a la aquí manejada. Como bien indicó LEROI-GOURHAN $(1971,226)$ los etnólogos se dedicaban más a estudiar aquello que hace diferente a las distintas culturas que lo que hay de fisiológicamente común a toda la especie humana. Por ello, la redefinición de cadena operatoria realizada por este autor se realizó desde un plano estructuralista y una concepción idealista. Para LEROI-GOURHAN (1971: 226) las cadenas operativas que podíamos encontrar en una "cultura" dependían del juego proporcional entre la experiencia individual idéntica a la del animal y la educación en la cual el lenguaje toma parte, siempre determinante. Así en todo análisis se debían tener presentes 3 planos: el biológico-educativo que imprime los datos de la tradición, el comportamiento maquinal que se adquiere a través de la experiencia, inscrito en el comportamiento gestual y el lenguaje y la existencia de comportamientos lúcidos a través de los cuales se consigue crear nuevas cadenas operativas. Todo ello depende de los niveles de funcionamiento del aparato neuropsíquico humano. De este modo se consideraba que a pesar de que lo determinante siempre era el aparato anatomo-fisiológico individual, se debía admitir que el comportamiento operativo espontáneo se encontraba recubierto por el comportamiento adquirido a través de la comunidad social (LEROI-GOURHAN, 1971, 227).

Los estudios posteriores ampliamente desarrollados en toda Europa, aunque intensamente en Francia y Bélgica (KARLIN et alii,
1991; CAHEN et alii, 1980; CAHEN, 1984; BINDER y PERLÈS, 1990; BOEDA, 1992, PELEGRIN, 1991) se han centrado en el estudio de las cadenas operativas líticas de un buen número de asentamientos, e incluso territorios, teniendo como marco referencial esta perspectiva teórica (GENESTE, 1991a, 1991b; BOEDA, 1992). No obstante, en los últimos quince años la investigación se ha orientado de forma casi exclusiva hacia la especialización en cada uno de los procesos, perdiéndose incluso la perspectiva analítica general otorgada por el concepto de cadena operativa. Podemos decir que del estudio de las cadenas operativas líticas se ha pasado al análisis de eslabones de la misma de forma aislada. Únicamente se realizan estudios cerrados en sí mismos referidos exclusivamente al aprovisionamiento de materias primas (RICQ DE BOUARD, 1981; OROZCO, 1996), tecnología (BOEDA et alii, 1990), experimentación lítica (TIXIER et alii, 1980; GALLET y TEXIER, 1991), remontajes (KARLIN, 1991), traceología (ANDERSON-GERFAUD et alii, 1987; CAUVIN, 1983; CAHEN y CASPAR, 1984; UNGER-HAMILTON, 1983, 1985, 1988, 1989; PLISSON, 1991, etc), e incluso, procesos postdeposicionales. No es que este hecho sea perjudicial, todo lo contrario, los estudios especializados son necesarios, pero su desarrollo también tiene sus inconvenientes cuando está ausente una estructura de conjunto dentro de un marco teórico adecuado y progresivo (SCHIFFER, 1983). Ello limita, como señaló RAMOS MILLÁN $(1982,408)$ el potencial de las inferencias conductuales ya que éstas no quedan integradas en los marcos socioculturales.

En los últimos años, se ha continuado realizando aportaciones teóricas sobre el concepto de cadena operativa desde una doble perspectiva: por un lado idealista, y por otro, tecno-económico.

Desde la primera, el objetivo es el estudio de un conjunto de operaciones técnicas articuladas temporal y espacialmente para la elaboración de diferentes tipos de productos, poniendo énfasis en la descripción de los instrumentos de trabajo, en la secuencia de los gestos técnicos, en la comprensión del comportamiento humano, especialmente en el proceso psíquico individual y en la acción desarrollada por el artesano en la cadena operativa (PELEGRIN, 1985; 1990; PIGEOT, 1991; KARLIN, 1984; PLOUX, 1979).

Para la segunda, la de corte tecnológico, se trata de establecer y describir el grado de complejidad tecno-económica alcanzada por los 
grupos humanos en la elaboración de los instrumentales líticos, fundamentalmente en relación con la optimización de energía y tiempo a través del desarrollo de estrategias complejas de gestión de los recursos líticos disponibles (TORRENCE, 1989).

En ese sentido, se han desarrollo nuevos conceptos, como son los de economía de "debitage" y economía de materias primas (PERLĖ, 1991), que vienen a enriquecer el concepto de cadena operativa, aunque ésta última entendida exclusivamente como los procesos de obtención de materias primas y los de producción de soportes, y a describir mejor el amplio abanico de procesos concretos de producción lítica -desde la perspectiva fundamentalmente tecnológica- que pueden haber sido desarrollados por las comunidades prehistóricas, tanto de forma sincrónica como diacrónicamente.

Al mismo tiempo, desde otra posición teórica como es el materialismo cultural, se han realizado algunas aportaciones con una visión más globalizadora. RAMOS MILLÁN (1982) propuso un modelo conceptual sobre los artefactos líticos en los contextos sistémicos -en palabras de SCHIFFER (1972; 1976)-. Dado que no podemos hacer una exposición detenida de sus aportaciones, RAMOS $(1982,411)$ considera que los artefactos líticos tallados nos pueden informar de dos fenómenos culturales como son lo que denomina como Tecnología de Manufactura -manufactura de artefactoscentrado en la obtención, transformación y distribución de elementos duraderos y Tecnología de Subsistencia -agricultura, caza, pesca, recolección - centrada en los mismos procesos que la anterior pero de elementos no duraderos, fundamentalmente, alimentos.

Aunque el trabajo de RAMOS MILLÁN (1982) es un buen intento de orientar el estudio de los artefactos líticos tallados hacia análisis sintéticos, es evidente que no se ha analizado la producción lítica como unidad, como proceso general concatenado, integrado por la producción, distribución, intercambio y consumo, ni tampoco ha interesado el marco de relaciones sociales de producción bajo el cual se posibilita la producción.

En las investigaciones han primado aspectos que insisten en plantear que las actividades técnicas están integradas socialmente y que para ello es necesario el aprendizaje (PELEGRIN, 1990, 122). De este modo los procesos concretos de producción lítica son considerados como algo estático, donde los suje- tos sólo repiten lo aprendido. Desde nuestra perspectiva, ésta debe ser considerada como algo dinámico, en continua transformación y donde los agentes sociales intervienen activamente.

En este sentido, una de las características implícitas de cualquier producto o desecho arqueológico es su dinamismo. Su dimensión temporal no se circunscribe al lapso de tiempo que cubre desde que fueron manufacturados, teniendo en cuenta el conjunto de procesos previos, hasta el momento en que son destruidos o descartados definitivamente. Más bien, una vez que entran a formar parte de un contexto arqueológico continúan en transformación permanente como consecuencia de múltiples factores como ya ha expuesto SHIFFER (1972).

No obstante, cada producto tiene un período de uso y al mismo tiempo, la función y las necesidades que cubren tienen a la vez un período de duración, hasta que otro objeto sea creado para la misma labor, aunque difiera morfológicamente del anterior, mejorando su efectividad. Sin embargo, no es el tiempo la condición que cambia al producto, sino que más bien son los cambios en general, que durante el desarrollo de la vida cotidiana (VELOZ, 1984) se dan en relación con las actividades que se realizan -la forma como se ejecutan y la calidad o intensidad de las necesidades (VARGAS, $1990,30)$ - y, posteriormente, los diferentes procesos naturales o sociales que actúan durante su fase de contexto arqueológico.

Durante la vida cotidiana de cualquier comunidad se desarrollan una serie de procesos de trabajo articulados dedicados a la transformación de la materia prima que siempre suponen una estrategia de reducción lítica, en unos casos más complejas que en otras. Las posibilidades de obtención de un producto con unas características determinadas a partir de un bloque de materia prima lítica son limitadas, siendo en la mayoría de los casos muy difícil la definición de la secuencia de reducción lítica completa que los ha producido (NEWCOMER, 1975; COLLINS, 1975).

No obstante, podemos teorizar sobre una serie de estadios o etapas concatenadas, donde se articulan en una secuencia lógica y temporal toda una serie de procesos de trabajo para la obtención, manufactura y mantenimiento de productos líticos (Figura 1). Podemos referirnos por tanto, a toda una serie de procesos que se realizan durante el estadio que constituye lo que denominamos como la vida cotidiana de cualquier grupo humano (BATE, 1998) -búsqueda de recursos natura- 


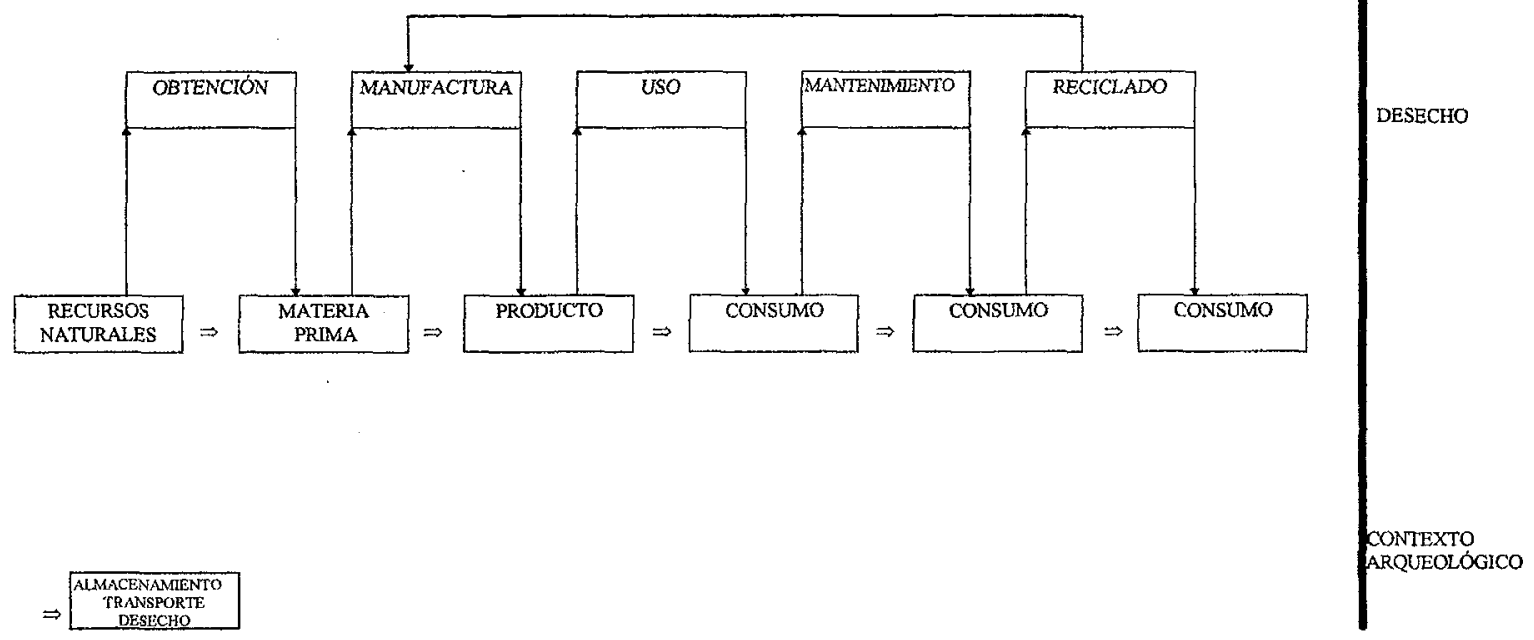

Figura 1: Esquema general del proceso productivo.

les, procesos de aprovisionamiento de materias primas, procesos de manufactura, procesos de consumo, procesos de mantenimiento y procesos de reciclado, desecho intencional o no intencional- y durante el estadio de contexto arqueológico - procesos de alteración, reclamo- (Figura 1 y 2 ).

\section{Procesos de obtención de materias primas}

En la naturaleza existen un buen número de rocas y minerales con diferentes caracterís- ticas -dureza, resistencia, ductibilidad, fracturación, etc- susceptibles de ser empleados por las sociedades humanas para cubrir sus necesidades. La búsqueda y selección de esta serie de recursos naturales constituyen los primeros procesos de trabajo realizados por los seres humanos. La prospección y conocimiento de los espacios naturales y/o transformados en los que viven las comunidades humanas se constituye como el paso previo para localizar los diferentes recursos litológicos existentes y para la selección de aquellos adecuados por sus características.
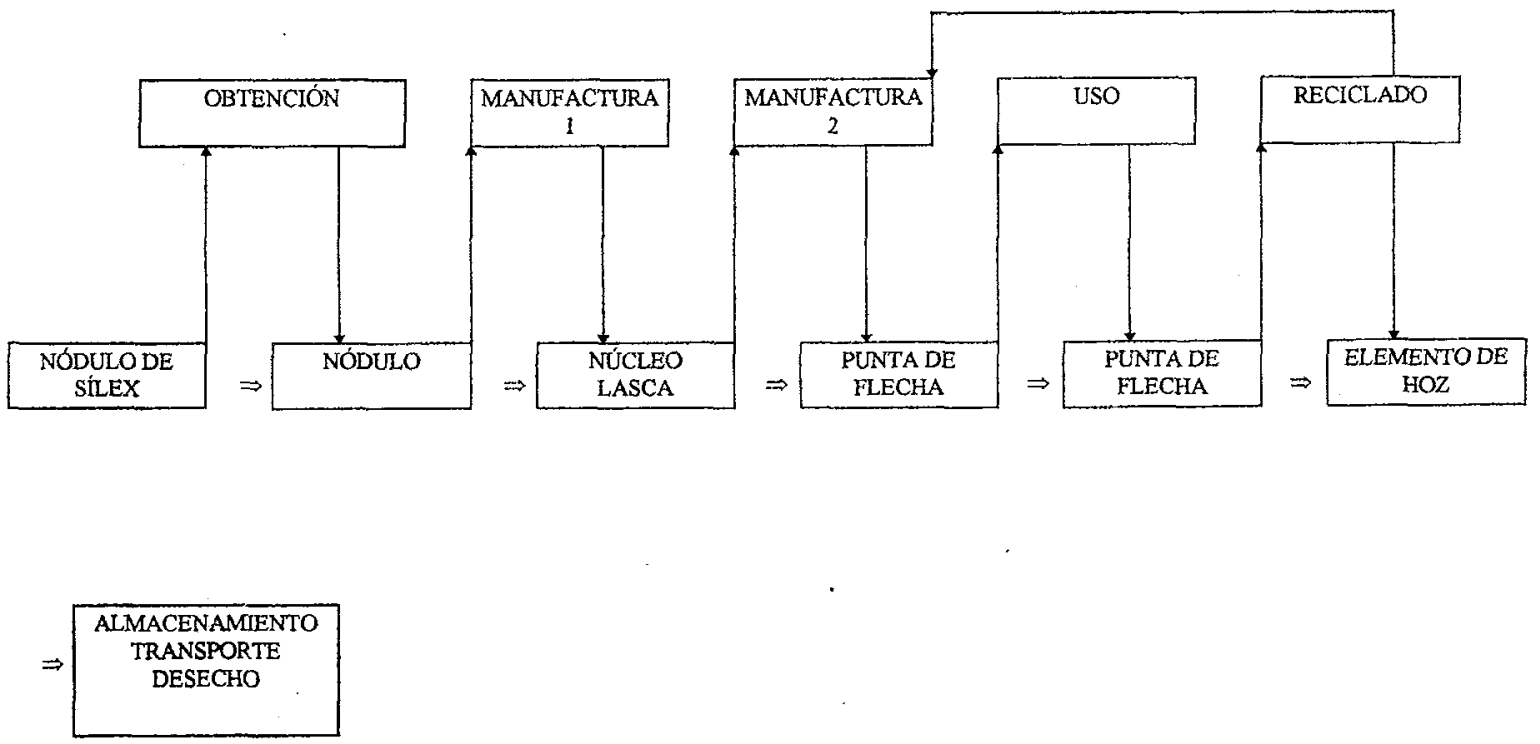

Figura 2: Ejemplo del proceso productivo. 
Es evidente que la disponibilidad de recursos naturales en las proximidades de los asentamientos no es suficiente para que una comunidad los explote. Es necesario, además, reconocer al recurso natural, hecho que podemos situar en íntima relación con el grado de desarrollo técnico, históricamente determinado, es decir, con el conocimiento que el grupo posee del medio ambiente, la capacidad tecnológica del grupo y la significación social determinada por la necesidad social que determinará su función (VARGAS, 1990, 46).

En el momento en el que un recurso natural es seleccionado para su uso por un grupo humano pasa a ser materia prima. Pero antes de iniciar los procesos de transformación de la materia prima, es necesario ejecutar diversos procesos de trabajo para la obtención de la misma. La realización de labores complejas como la minería o la cantería, o formas más simples como el laboreo superficial (CARRIÓN et alii, 1993) son diferentes procesos de trabajo que pueden implicar, en algunos casos, una importante inversión de fuerza y medios, e incluso, un elevado grado de organización técnica del trabajo.

Ahora bien, casi la totalidad de las investigaciones realizadas hasta la fecha han estado orientadas exclusivamente, por un lado, a la identificación de las materias primas líticas empleadas por las comunidades prehistóricas $y$, por otro, a establecer la localización de las fuentes de suministro o de abastecimiento de las diferentes rocas identificadas. Entre ambos procedimientos se establece una clara relación de dependencia al plantear un principio de identidad entre las características de las materias primas localizadas en un yacimiento arqueológico y las existentes en el afloramiento de donde puede proceder. A través de la caracterización petrográfica y/o mineralógica de los materiales líticos arqueológicos y de su contrastación con la documentación geológica disponible a diversos niveles -local, regional, o interregional-, se ha conseguido identificar las fuentes de suministro, teniendo presente que la proximidad o lejanía de los yacimientos a las áreas-fuente es suficiente para considerar que los procedimientos de adquisición de la misma se han realizado de forma directa -suministro territorial- por parte de las mismas comunidades 0 , indirecta -suministro extraterritorial- a través del intercambio con otras comunidades, sin que se explicite claramente donde se establece el límite entre lo que se considera próximo o lejano. En este sentido, RAMOS MILLÁN
$(1984,111)$ ya destacó que no existen datos para cuantificar el radio de acción medio que posibilite una explotación directa, y que, precisamente, la determinación de las fuentes de suministro y la interpretación del sistema de suministro pasa por la determinación del radio territorial de explotación de cada asentamiento. En su propuesta expone que, con la aplicación del Site Catchment Analysis, se podrían establecer los diferentes radios de explotación territorial de los asentamientos, y así, determinar los límites de la explotación directa en función de los casos concretos que se traten.

Esta perspectiva defendida por RAMOS (1984) es, en parte, la dominante en los estudios líticos de sociedades móviles, con un modo de vida cazador-recolector (DEMARS, 1982; TAVOSO, 1984; GENESTE, 1991), pero no ha sido la más desarrollada por los investigadores que se dedican al estudio de las sociedades con un modo de vida agropecuario (COGNE y GIOT, 1952; LE ROUX, 1979; RICQ DE BOUARD, 1981). Ésta ha consistido en el enfoque inverso, a saber, establecer la distribución de artefactos desde determinadas fuentes de suministro que por sus características singulares eran fácilmente detectables. Un magnífico ejemplo lo constituye el complejo de las minas de variscita de Can Tintorer en Gavà (Barcelona) (EDO et alii, 1990; 1992a; 1992b; 1995).

Pero quizás, en este punto sea necesario destacar la heterogeneidad de técnicas empleadas para establecer ese principio de similitud entre los soportes líticos documentados en los contextos arqueológicos y las posibles fuentes de suministro. Entre ellos cabe destacar la observación macroscópica (DEMARS, 1982; TORTI, 1983; MORALA, 1984, GENESTE, 1988; ROSSER, 1990), la observación microscópica (MASSON, 1979; RICQ DE BOUARD, 1987; BARRERA et alii, 1987; OROZCO, 1992), la determinación de restos micropaleontológicos (MAUGER, 1984), la activación neutrónica (LUEDTKE, 1979), la fluorescencia de rayos $X$ (HALL, 1960; WARD, 1974), la difracción de rayos X (TAKÁCS-BIRÓ, 1986), así como otras técnicas como la absorción atómica (SIEVEKING et alii, 1970).

Ante las dificultades que plantea el empleo de una sola técnica (TERRADAS et alii, 1991), la opción más viable que se viene manejando en los últimos años es el empleo de varias técnicas de forma complementaria, además de contar con equipos de trabajo interdisciplinares, especialmente con geólogos. 
Pero el problema principal no pasa por las técnicas que se pueden emplear para la caracterización de los materiales arqueológicos, sino en el hecho de que la contrastación de la información obtenida de las muestras, se realiza habitualmente con la información geológica disponible en la actualidad. Y ésta no es otra que la cartografía geológica a diferentes escalas. Con la determinación petrográfica y minerológica de los diferentes soportes líticos, se inicia una asociación inmediata a un contexto geológico determinado del que puede proceder. De este modo, se sugiere una referencia cartográfica donde localizar los diferentes afloramientos que hayan podido ser obtenidos. Esa identificación se establece en función de la información cartográfica disponible y a lo sumo, con algún apoyo documental complementario.

Sin embargo, la cartografía geológica responde a los objetivos trazados por los geólogos, pero nunca a los intereses de los arqueólogos. Las preguntas planteadas por los geólogos no son las mismas que las que planteamos en nuestro campo de estudio.

Ahora bien, ello no significa que la información geológica disponible no sea válida. Más bien todo lo contrario. Debe ser una base sobre la que empezar a trabajar las posibles áreas-fuente potenciales, aunque tal como plantean CARRIÓN y OTROS (1994), todo intento de establecimiento de las fuentes de obtención de materias primas pasa necesariamente por contar en la dinámica de trabajo con una prospección geoarqueológica territorial.

La prospección se puede convertir en el vehículo adecuado para aportar un conocimiento íntegro del medio geológico en función de las preguntas que nos planteemos. A través de la misma, conseguiremos la localización exacta de los diferentes recursos naturales potenciales, su muestreo sistemático, y la creación de una litoteca específica de referencia para su contraste con los utensilios prehistóricos. A partir de aquí, estaremos en condiciones de preguntarnos por la demanda específica de recursos, la articulación a diferentes escalas de las redes de suministro, sobre los principios que rigen los diferentes patrones de asentamientos, y sobre los procesos de trabajo empleados en la obtención de las materias primas.

Al mismo tiempo, labores como el traslado de la materia prima, bien a áreas de actividad -más o menos cercanas de los afloramientos, bien a los mismos asentamientos, deben contemplarse como una actividad más indispen- sable para que se lleve a cabo la manufactura. Una vez seleccionada la materia prima, en función de sus características y de las necesidades socialmente establecidas, se iniciarán los procesos de manufactura que conducirán a su adecuación morfológica.

\section{Procesos de manufactura}

Se trata del conjunto de acciones, de labores técnicas, destinadas a la transformación de la materia prima en productos, implicando en todos los casos la reducción y/o adecuación de los bloques de materia prima, y como consecuencia, la generación de desechos, en principio, no aprovechables.

Son múltiples los procedimientos técnicos susceptibles de ser empleados siguiendo una secuencia lógica de reducción lítica. Tradicionalmente, se ha hecho una primera distinción entre los productos obtenidos por procesos de talla exclusivamente, y aquellos caracterizados fundamentalmente por la última técnica aplicada para su acabado definitivo como es el pulido de sus superficies -aunque no necesariamente-.

Para la primera se pueden distinguir múltiples procesos secuenciales de fracturación de las rocas seleccionadas. Mediante la percusión y/o la presión se pueden llevar a cabo múltiples y diversas secuencias de reducción de bloques de materia prima con el fin de obtener soportes o productos con la forma y tamaño requeridos. Se pueden realizar desde secuencias simples generando soportes indiferenciados o no normalizados a complejas, creando soportes diferenciados o normalizados (PERLĖS, 1991), que suponen desde la preparación y conformación de núcleos de donde obtener soportes menores -lascas, hojas- con los que elaborar los productos a través de la modificación de sus bordes y superficies mediante la aplicación de fracturas y retoques, hasta la realización de pequeñas modificaciones de los bordes mediante retoques o fracturas. Aquí podrían tener cabida algunas de las estrategías de gestión de recursos líticos más elaboradas y complejas como son los denominados como economía de "debitage" y economía de materias primas (PERLĖS, 1991).

Para la producción pulida podemos señalar similares procesos. Para su elaboración normalmente se emplea la técnica de la percusión, la presión y la abrasión en una articulación de procesos donde se puede combinar el desbastado de los bloques de materia prima, el 
repiqueteado, el aserrado, la perforación y el pulido de las superficies.

A los procesos aludidos, cabe unir los de enmangue, montaje o sujección sobre mangos o soportes de distintos tipos de materia prima madera, hueso, cuero, etc-.

Por lo tanto, las secuencias de manufactura lítica no pueden ser consideradas como eslabones de una cadena, como procesos cerrados y unilineales, sino más bien todo lo contrario, como secuencias abiertas, múltiples y dinámicas que en principio tiene una lógica temporal, un orden lógico de elaboración.

La principal unidad de análisis donde podremos observar los procesos de manufactura serán las áreas de actividad de producción (Figura 3) (MANZANILLA, 1986; SARMIENTO, 1996).

\section{Consumo}

Constituye el momento o el estadio en el que el producto se convierte realmente en producto, es decir, se lleva a cabo su empleo o uso en las labores para las que fue elaborado. El consumo puede darse desde que se realiza el aprovisionamiento de una materia prima, sin pasar por procesos de manufactura, o una vez que la materia prima ha sufrido los procesos de manufactura requeridos. Aunque la distribución y el intercambio se pueden dar en cualquier momento del proceso productivo, antes del uso efectivo del producto es cuando existe una mayor probabilidad de realizarse, especialmente en sociedades donde se ha adquirido un grado considerable de división social del trabajo. El consumo de los productos también se realiza después de la realización de procesos de mantenimiento y de reciclado. La principal unidad arqueológica donde se puede observar el consumo será precisamente en las áreas de actividad de consumo (MANZANILLA, 1986; SARMIENTO, 1996).

\section{Procesos de mantenimiento}

Los procesos de mantenimiento constituyen un conjunto de actividades laborales a través de las cuales se consigue por un lado, mantener la efectividad laboral del producto $y$, por otro, alargar la vida útil del mismo hasta que ya no se puede obtener rendimiento. Para sociedades donde no existe un alto grado de división social, las labores de mantenimiento de los productos debe considerarse como una labor individual, propia de quien lo consume. Los proce- sos de mantenimiento deben tenerse muy presentes en el estudio de instrumentos de trabajo, es decir, en el conjunto de productos que intervienen en el consumo productivo.

El mantenimiento afecta especialmente a las partes activas de los instrumentos de trabajo. Las técnicas empleadas para el reavivado de las partes activas fueron principalmente la abrasión, el retoque mediante presión y/o percusión o el repiqueteado. El estudio traceológico de los instrumentos se constituye como una de las principales herramientas en su determinación.

\section{Procesos de reciclado}

Se trata del conjunto de actividades laborales encaminadas a la transformación de un producto en un nuevo producto con características y usos diferentes. Aunque el reciclado puede realizarse por múltiples causas, la más frecuente en lo que afecta a los productos líticos es la que se refiere a los instrumentos de trabajo que después de un prolongado uso y mantenimiento, ya no están en condiciones de cumplir con las labores para las que había sido elaborado. En múltiples ocasiones la fractura o agotamiento del mismo durante su consumo conlleva su reciclado. En su reciclado, todo producto lítico puede conservar, o bien buena parte de los atributos o características de su configuración inicial, permitiendo plenamente su reconocimiento, o bien todo lo contrario, anular o suprimir buena parte de los mismos. Los cambios morfológicos observados de visu o a través del empleo de instrumentales como lupas binoculares o microscopios, constituyen herramientas adecuadas en su determinación.

Quizás, como reflexión nos gustaría reseñar que tanto los procesos de mantenimiento como los de reciclado son aspectos que no han suscitado el interés que realmente merecen y al que con toda seguridad estuvieron sometidos buena parte de los instrumentos de trabajo que se documentan en los contextos arqueológicos.

\section{Desecho}

Es el momento en la vida cotidiana de cualquier sociedad en el que se produce el descarte definitivo del producto como consecuencia de múltiples causas, en unos casos intencionales -desecho, abandono, ajuar de una sepultura, etc.- o no intencional -pérdida, almacenamiento, depósito, etc.-, siendo la más 


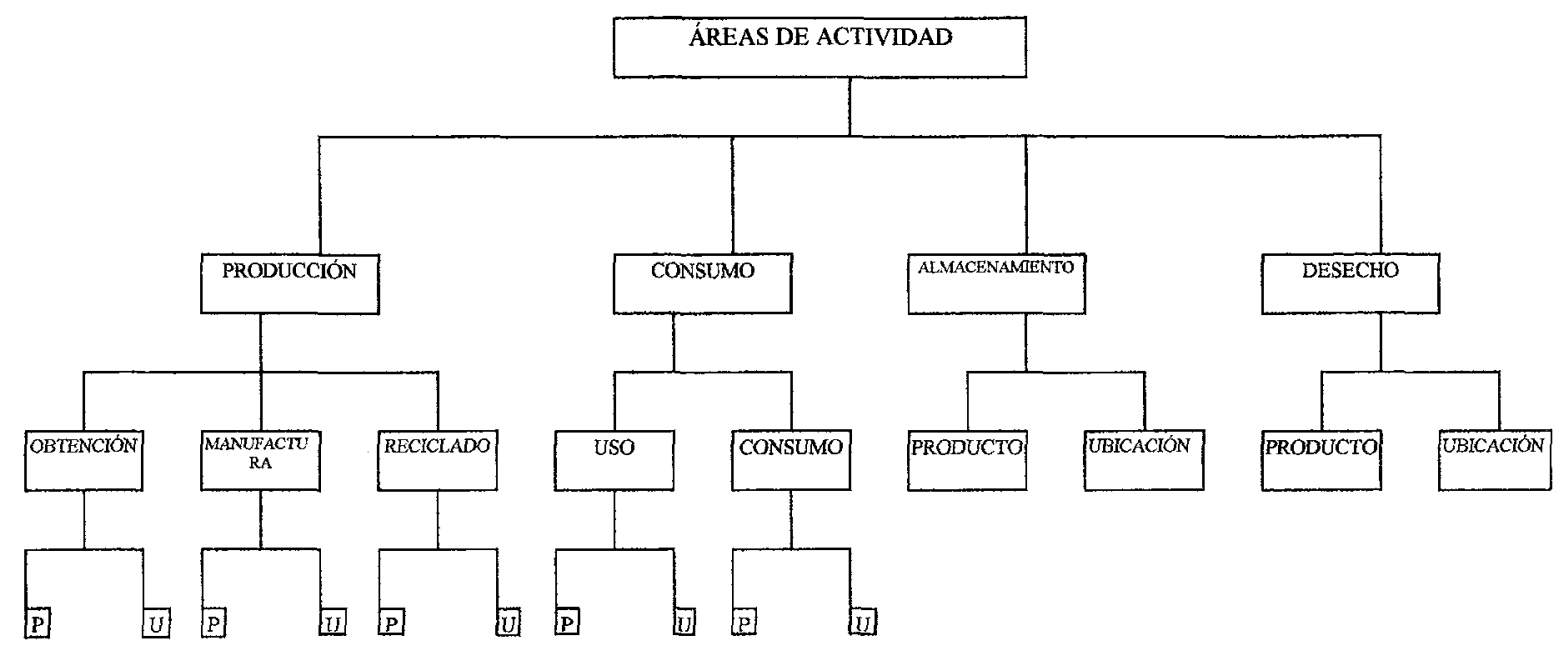

Productos

Ubicación

Figura 3: Esquema general de las principales àreas de actividad según G. Sarmiento (1996).

frecuente su consumo definitivo y su incapacidad para seguir siendo efectivo. Será en las áreas de actividad de desechos donde podremos documentarlos (SARMIENTO, 1996). Así, el producto pasa de un contexto-momento determinado a un contexto arqueológico (SHIFFER, 1972; BATE, 1998) con unas condiciones deposiciones concretas -contextos primarios, secundarias, etc-, y a partir de este momento, son varios los procesos -sociales y naturalesque pueden afectar a su estado (Figura 3).

\section{Procesos postdeposicionales}

En el momento en el que los componentes de un contexto-momento se desvinculan de la actividad humana, estamos ante un contexto-arqueológico (BATE, 1996, 95; 1998). La vida cotidiana (VELOZ, 1984) podríamos caracterizarla como la sucesión de contextos-momento constituidos por actividades que permanentemente generan contextos arqueológicos. A partir de este momento, los individuos dejan de ser el elemento causal de la dinámica de los componentes. Las propiedades de los componentes y su distribución espacial pasan a ser los indicadores fundamentales para el análisis de los contextos arqueológicos, aunque para ello sea necesario, en primer lugar, conocer la historia del contexto arqueológico en cuestión, sin olvidar que no existe ninguna unidad es- tratigráfica que no se haya visto afectada por procesos postdeposicionales o que exclusivamente sea el resultado de un único evento.

Las débiles bases teóricas con las que se contaba hasta hace muy pocos años para enfrentarse con la observación de los registros arqueológicos y el tratamiento que se hacia de los datos desde la arqueología tradicional e incluso desde la arqueología procesual, al considerar algunos de sus miembros que éstos no eran problemáticos, llevó a SCHIFFER (1972, $1976,1977,1981,1983,1988)$ a desarrollar una teoría con la que acercarse a la conducta humana y poner en duda los resultados de algunos trabajos procesuales. Aunque, en un principio, la denominada arqueología conductual fue considerada casi como una nueva variedad de arqueología, desde hace unos años ya se valora como una serie de principios teóricos mediadores que sirven para interpretar los procesos de formación del registro arqueológico y en concreto, para la creación de una teoría de la historia de los contextos arqueológicos (BATE, 1998).

Los factores que SCHIFFER (1991) ha distinguido en los procesos de formación del registro arqueológico se engloban bajo dos grandes tipos como son los denominados culturales -socioculturales para SARMIENTO (1992) y sociales para BATE (1992; 1996)- y no culturales -naturales (SARMIENTO, 1992; BATE, 1998)-. 
Los contextos-momento pueden pasar a ser contextos arqueológicos de varias formas. De forma normal se puede producir una acumulación de actividades en un espacio dado, generándose una deposición de los componentes, o por el contrario, se puede producir un abandono súbito o paulatino de los espacios ocupados, lo que incide de diferente forma en la presencia o ausencia de determinados componentes.

Ahora bien, en el paso de contexto momento a contexto arqueológico y durante la historia de éste último se pueden producir transformaciones por causas sociales o naturales. Los factores sociales son aquellos en los que sociedades tanto contemporáneas como posteriores destruyen o modifican los contextos arqueológicos existentes, debido a diversas causas como pueden ser la reutilización de materiales, los cambios de funcionalidad, las prácticas agrícolas, e incluso la misma excavación arqueológica. Para SCHIFFER $(1991,40)$ la acción de los arqueólogos - por no insistir con los furtivos- es la más importante de las causas sociales que inciden en la transformación -o más bien destrucción- de los contextos arqueológicos.

Los principales conceptos que distingue SCHIFFER $(1977 ; 1991)$ para la definición de la historia de los contextos arqueológicos son los siguientes:

- Desechos o contextos primarios para referirse a aquellos artefactos, elementos, etc, dejados en el lugar donde se usan y que no han sido afectados o transportados del lugar por cualquier agente después de su deposición, aunque si procesos postdeposicionales.

- Desechos o contextos secundarios, aquellos que han perdido su asociación original a consecuencia de diversos tipos de factores que le han afectado.

- Reclamo cuando se da entrada a un artefacto de un contexto arqueológico a un contexto momento.

- Perturbación del contexto arqueológico al conjunto de modificaciones sociales del mismo.

En cuanto a los procesos naturales que pueden afectar a los contextos arqueológicos SCHIFFER (1991) ha distinguido entre:

- El deterioro que pueden sufrir los artefactos como consecuencia de su interacción con el medio ambiente. Procesos de corrosión por acidez, procesos de patinación, etc. son problemas demasiado frecuentes en los contextos arqueológicos excavados.

- Las posibles alteraciones de los yacimientos por múltiples factores, principalmente, por la acción nociva de múltiples especies de animales -lombrices, conejos, topos, etc.- o por condiciones climatológicas en lugares con cambios bruscos de temperatura gelifracción-.

- Procesos regionales en los que la abundante vegetación puede facilitar su transformación, aluviones o fuertes procesos erosivos. Del mismo modo, la acción eólica también puede facilitar su conservación o acelerar su destrucción.

En definitiva, un conjunto de factores humanos y naturales cuya combinación ocasiona la formación de los yacimientos arqueológicos hasta el momento en el que el arqueólogo decide intervenir en él.

Teniendo en cuenta toda esta serie de factores, el arqueólogo además de realizar su actividad con el máximo de rigor, debe poder determinar la contemporaneidad de las diferentes áreas de actividad, unidades de ocupación y asentamientos, determinar la duración y fecha posible de las mismas y entender la historia del contexto arqueológico que se está trabajando a partir del establecimiento de la relación entre las actividades documentadas, las deposiciones y el tiempo en el que se realizaron (SARMIENTO, 1992, 50).

\section{Reclamo}

Aunque el reclamo se incluye como uno de los procesos sociales que suponen el deterioro de los contextos arqueológicos, consideramos necesario realizar algunas puntualizaciones, debido a que esta actividad pudo ser una forma cotidiana de obtención de todo tipo de recursos aprovechables, especialmente los líticos. De este modo, determinadas fuentes de materia prima pudieron ser empleadas de forma continuada por parte de comunidades humanas durante varios milenios, aprovechando en buena medida algunos de los desechos generados con anterioridad. Lo mismo se puede señalar para algunos contextos arqueológicos que constituyeron fuentes de materia prima. Por lo tanto, se podría dar la circunstancia de que un contexto arqueológico sea una fuente de materia prima de extraordinario valor en función de la calidad de los recursos o proximidad a los núcleos de hábitat. De este modo, es posible que algunas de las evidencias líticas docu- 
mentadas en yacimientos arqueológicos sean reclamos y su no identificación como tales puedan llevarnos a errores sobe el desarrollo tecnológico de la sociedad en estudio (JOVER, 1997).

Con todo, cualquier sociedad concreta diseña una tecnología con la que apropiarse de la naturaleza y satisfacer sus necesidades, materializándose a través de la aplicación de diferentes técnicas en el conjunto de procesos de trabajo que constituyen la producción. " $\mathrm{La}$ tecnología, en consecuencia, es la conjunción en lo producido del cómo y el por qué se produce y de qué se satisface" (VARGAS, 1990, 48).

Dentro de este esquema que constituyen los procesos de producción lítica, la distribución y el intercambio pueden darse en cualquier momento de los procesos realizados durante la vida cotidiana de cualquier sociedad. A través de su identificación en las diferentes áreas de actividad, unidades ocupacionales y yacimientos, podremos descubrir cómo se producen, cómo se distribuyen, cómo se intercambian y cómo se consumen los productos líticos. Pero previamente será necesaria e imprescindible la identificación de los procesos de formación de los contextos arqueológicos y tenerlos en cuenta en la determinación de las diferentes trazas o información contenida en los artefactos líticos (SCHIFFER, 1983; RAMOS, 1988, 414). $Y$ en función de ello, y del conjunto de procesos productivos de la sociedad en estudio se podrá determinar cuáles son las relaciones sociales establecidas en la producción.

\section{SOBRE LOS PROCESOS DE CLASIFICACIÓN DE LOS PRODUCTOS LÍTICOS}

Si tuviésemos que responder sobre cuál es la actividad más frecuente en la vida de un arqueólogo tendríamos que señalar, muy a nuestro pesar, que es la de clasificar. Pasamos hora tras hora estableciendo casilleros cada vez más sofisticados y minúsculos donde ir introduciendo todos aquellos restos materiales que documentamos en las diferentes actividades arqueológicas. Pero cabría preguntarnos para qué realizamos esta actividad que absorbe nuestro tiempo. De modo habitual, se admite que la clasificación de los objetos se realiza para ordenar el conjunto de materiales y sintetizar de forma clara sus características, intentando que los tipos establecidos sean lo más fácilmente reconocibles para el resto de los investigadores.
Esta es la justificación más importante utilizada como criterio para evaluar la calidad de las tipologías en uso. Pero, ¿Cómo concebimos realmente los procedimientos clasificatorios? ¿Para qué los utilizamos? ¿Qué criterios utilizamos para la elección de los atributos?.

No es necesario profundizar ni extendernos en demasía sobre este aspecto, ya que en numerosas ocasiones se ha señalado que los procedimientos clasificatorios tenían como objetivo fundamental el establecimiento y la diferenciación de áreas culturales, así como la fijación de fechas relativas con la simple documentación del considerado "fósil director".

Sin embargo, los procesos de clasificación no han estado ni exentos de crítica, ni ha existido unanimidad en su aplicación, pudiéndose señalar, después de más de un siglo de investigaciones, que casi existen tantas propuestas tipológicas como investigadores. Es más, el desarrollo de la Prehistoria como disciplina no se puede entender si no tenemos presente el papel que han jugado los sistemas de clasificación.

Han sido varias las técnicas e incluso disciplinas que, a través de su aplicación y de forma hipotética, han facilitado y permitido, reconstruir la secuencia global de los procedimientos técnicos relacionados con las producciones líticas, especialmente con la manufactura de los utillajes líticos, a través del reconocimiento de las características y atributos que presentan.

En primer lugar, se ha de destacar la contribución fundamental que supone la experimentación actual en la reproducción de los diferentes procesos de elaboración y uso de buena parte del instrumental prehistórico, tanto tallado como pulido (BORDES, 1950; TRIGHAM et alii, 1974; TIXIER et alii, 1980; SEMENOV, 1981; KEELEY, 1980; PELEGRIN, 1984, 1991; BEYRIES, 1988; GALLET y TEXIER, 1991; BOËDA, 1992; JARDÓN, 1990; FÁBREGAS, 1992; GONZÁLEZ e IBÁÑEZ, 1994; RODRÍGUEZ, 1990; etc.). La considerable labor realizada ha permitido facilitar la identificación de los diferentes soportes que permiten inferir los procesos laborales en los que participa el género humano y desarrollar ampliamente diferentes líneas de trabajo, utilizando los resultados obtenidos como fuente de hipótesis.

En segundo lugar, la sistemática labor desarrolla en el estudio de las producciones líticas talladas de los grupos de cazadoresrecolectores, ha permitido reconstruir procesos completos de explotación de bloques de mate- 
ria prima a partir de la realización del remontaje de los mismos (VILLA, 1978; CAHEN et alii, 1980). A través de este tipo de análisis se ha conseguido conocer en detalle la secuencia completa de reducción de núcleos.

$Y$, en tercer lugar, la existencia de poblaciones actuales que continúan fabricando una amplia gama de instrumentos líticos, recogidos en diversos trabajos etnoarqueológicos y antropológicos, también ha servido de base para la identificación de los procesos aludidos (GOULD, 1978; GALLAGHER, 1977; ANDERSON-GERFAUD, 1992; PETREQUIN y PETREQUIN, 1993, HAYDEN, 1979, etc.).

Si a ello le unimos el gran esfuerzo realizado en la normalización y establecimiento de la nomenclatura y terminología léxica empleada en la descripción de los soportes líticos y sus trazas (BREZILLON, 1968; LAPLACE, 1972; TIXIER et alii, 1980; MERINO, 1980, etc.), podemos indicar que estamos ante uno de los aspectos más sistematizados en las investigaciones prehistóricas.

A partir de toda esta información generada y de la amplia bibliografía existente sobre estudios líticos, en los yacimientos arqueológicos y más concretamente, en las unidades menores -unidades habitacionales $u$ ocupacionales, áreas de actividad- se pueden documentar toda una serie de soportes líticos con diferentes rasgos indicativos del momento de la secuencia de producción en el que fueron desechados. A grandes rasgos y sin querer detenernos en una exposición minuciosa de los mismos ya que existen numerosos trabajos mucho más específicos ( TIXIER et alii, 1980; BERNALDO DE QUIROS et alii, 1981; BAENA y LUQUE, 1990, etc) podrían documentarse: bruto.

\section{1.- Bloques de materia prima en estado}

2.- Bloques de materia prima en diversos estados de talla, de los que se obtienen otros subproductos de lascado, o simplemente, son desbastados, en función del producto que se pretende manufacturar. En cualquier caso, tanto si son desbastados para aprovechar los lascados como para configurar el bloque de materia prima, la característica fundamental es la existencia en su superficie de improntas de las distintas extracciones practicadas, conocidas como negativos de lascado.

A través de ellas podemos determinar en qué momento de la secuencia de explotación se encuentra. En el ejemplo concreto de la producción lítica tallada, se pueden documentar núcleos únicamente "catados", núcleos en proceso de preparación, configurados, en plena talla, agotados, e incluso reciclados. En relación con la producción lítica pulida, dado que el bloque de materia prima es el soporte modificado que se convierte en valor de uso, se pueden documentar las denominadas preformas, bloques desbastados en los que empieza a configurarse la morfología propia de la manufactura en proceso de elaboración. No obstante, los negativos pueden desaparecer por la aplicación de la técnica del repiqueteado en toda la superficie, y posteriormente del pulido.

3.- Productos de lascado, es decir, el conjunto de fragmentos de roca desprendidos del bloque de materia prima como consecuencia de procesos de talla o de desbastado y que aportan diversos grados de información. Dentro de la globalidad de estos soportes podemos distinguir:

3.1.- Debris o desechos de talla. Se trata, en general, del conjunto de fragmentos de roca de pequeño tamaño -lasquillas, astillas, esquirlas térmicas-, que no constituyen el objetivo de los procesos de talla o desbaste, pero que se generan como consecuencia directa de éstos.

3.2.- Productos de acondicionamiento o de técnica. Son soportes -flancos, aristas o crestas y tabletas de núcleos, etc.- que evidencian la preparación y procesos de desbaste que han sufrido los núcleos en su fase de configuración y aportan una valiosa información sobre las características de los mismos y de las técnicas de talla o de desbaste empleadas. Aunque puedan ser soportes modificables y aprovechables, tampoco son el objetivo central de los procesos de producción lítica, pero sí son indicativos de las diferentes estrategias de reducción de núcleos empleados.

3.3.- Productos de lascado de diferente morfología y obtenidos a partir de diferentes estrategias de explotación de núcleos -lascas, hojas o láminas- y que en el caso concreto de los productos líticos tallados, normalmente constituyen los soportes requeridos y aprovechables. Éstos ya pueden ser usados una vez obtenidos.

4.- Productos de lascado modificados, fundamentalmente, a partir de la aplicación de fracturas técnicas -percusión, flexión, etc- o mediante retoque -percusión, presión, etc-. En principio, la finalidad de su aplicación es la conformación de un soporte lítico mejor adaptado a las necesidades funcionales requeridas. 
Fundamentalmente, los productos de lascado modificados pueden documentarse, 0 bien en distintas fases de elaboración, o bien plenamente acabados.

5.- En la modificación de los productos de lascado también se generan debris o desechos, difíciles de distinguir de los de talla, especialmente, las lasquillas desprendidas por la aplicación del retoque.

6.- Productos usados, ya sea en un consumo productivo -instrumentos de trabajo-o no productivo -objetos de prestigio, adorno o diferenciación social-. La traceología es una destacada herramienta para reconocer los procesos de uso, así como de mantenimiento, especialmente, en los instrumentos de trabajo que intervienen en procesos laborales intensos y prolongados, y en los que se necesita disponer de una alta efectividad.

7.- Productos reciclados, es decir, productos usados -normalmente- que han perdido su efectividad y nuevamente son modificados para mantenerlos cubriendo una nueva necesidad.

Además, en las diferentes categorías de soportes señalados se pueden reconocer y observar todas una serie de atributos morfológicos que son el efecto de su uso, del empleo de unas determinadas técnicas, sistemas de explotación diferentes, o de sistemas de sujeción. En gran medida, su presencia o ausencia, permitirán reconocer aquellas variables relevantes respecto a los objetivos ya señalados.

Ahora bien, la base de casi todas las seriaciones materiales propuestas hasta la fecha, especialmente en lo que respecta a los utillajes líticos, se han establecido siguiendo para ello el sistema tipo-variedad. Una de las primera definiciones de tipo la debemos a KRIEGER $(1944,277-278)$ quien considera que es "una combinación específica y coherente de rasgos". Si a esta definición le unimos que el tipo es el elemento central de la tipología y la aportación adicional de ROUSE (1960) de que un tipo no es el conjunto de artefactos reunidos en un grupo por una clasificación, podemos indicar que, bajo estas condiciones, esta definición ha sido aceptada plenamente por un gran número de investigadores.

De este modo, el tipo era considerado como el esquema mental, es decir, un modelo ideal presente en la mente del artesano prehistórico, determinado por su cultura y que intentaba aplicarlo en el momento que empezaba a elaborarlo. La variabilidad existente dentro de los tipos se intentaba explicar a partir de varios factores como podían ser la existencia de diferencias individuales entre artesanos, la distribución geográfica dentro de una misma área cultural y cómo no, el factor temporal. Por ello, no es de extrañar que surgiera el concepto de variedad introducido por WHEAT, GIFFORD y WASLEY (1958), reflejando así, de forma más fiel, las particularidades de los tipos.

Por lo tanto, la tipología o procedimiento de clasificación más empleado en Prehistoria y considerada en ocasiones incluso como "ciencia que permite reconocer, definir y clasificar las diferentes variedades de útiles" (BORDES, $1960,1)$ no es más que un proceso taxonómico, es decir, una relación que se establece entre dos o más tipos de unidades, subordinadas unas a otras en una relación jerárquica de tipo inclusivo. Cada unidad superior es la unión de las unidades subordinadas a ella.

Con estos antecedentes, en 1971, DUNNELL (1978) establecía la diferencia entre agrupamiento y clasificación. Agrupamiento lo definía como "la creación de unidades de cosas (grupos)" mientras que clasificación "la creación de unidades significativas estipulando redundancias (clases)". Las clases no se pueden describir, sólo definir, mientras que un grupo es puramente fenomenológico, un conjunto de objetos reales, históricos, localizados en un tiempo y en un espacio.

Esto nos lleva a considerar de qué modo existe el "tipo". Teniendo en cuenta lo expuesto, el tipo como clase pertenece al mundo de las ideas, a la mente del analista y a los requerimientos de su investigación. Los tipos no se encuentran, no se pueden reconocer, sino que el investigador los elabora y pone los objetos de estudio en él, aunque en principio, no tienen porqué tener ninguna relación con una colección de materiales. Por el contrario, desde la perspectiva de grupo, los tipos existen en el material (SPAULDING, 1953; WATSON, LEBLANC y REDMAN, 1971, 127). Esta última ha sido la visión más extendida en el conjunto de propuestas clasificatorias.

Sin embargo, como señala TSCHAUNER $(1985,52)$ lo que es evidente es que los "tipos" de artefactos no se descubren, ni son inherentes al material, ni están preformados en él. Existen, en el plano teórico, un número infinito de posibles clasificaciones, ya que cada evidencia material tiene un número teóricamente ilimitado de atributos, siendo por lo tanto, la clasificación que se puedan realizar, nada más que una de las posibles. 
Desde esta perspectiva, la selección y delineación de cualquier clasificación, la elección de la escala de la clasificación, la definición de los atributos y sus nexos de unión son totalmente arbitrarios. Los atributos que seleccionamos y los tipos que creamos no son datos objetivos, ni son datos en bruto (TSCHAUNER, 1985, 53 ). Dado que los tipos son impuestos al material, creados por el investigador, y teniendo en cuenta que los atributos siempre son arbitrarios, lo más lógico es que tengan una relación perfectamente definida y estrecha con las hipótesis que estemos evaluando, al constituirse en los instrumentos de medición de las mismas. De igual modo que las similitudes y diferencias de las evidencias materiales que caen dentro lia cada una de las clases claramente instrumentales, se constituyen en los datos empíricos utilizables. En conclusión: "No puede haber ninguna clasificación en un vacio teórico". "No existe observación libre de teoría" (TSCHAUNER, 1985, 54).

Bajo estas premisas, no tiene sentido seguir estudiando o documentado todo tipo de atributos sin tener conciencia de los problemas que se deben evaluar, como tampoco es coherente considerar que una colección determinada está estudiada definitivamente, ya que se puede volver a clasificar con otros problemas en mente.

Por todo ello, compartimos la idea de TSCHAUNER $(1985,65)$ referente a que hemos de considerar que las clasificaciones son exclusivamente, instrumentos de medición de las asociaciones y variaciones de las diferentes variables elegidas en una investigación, interesándonos aquellos aspectos del material que sean relevantes para el problema investigado. Así, es preferible considerar a una colección de artefactos como un continuum de evidencias materiales fruto de la actividad humana, más o menos similares unos a otros, y formar según interese, diferentes unidades descriptivas clasificatorias, en las que admitamos la arbitrariedad de los atributos seleccionados, pero que en cualquier caso, estén relacionados con los objetivos a evaluar. Por ello, estamos de acuerdo en considerar que las clasificaciones son importantes desde el punto de vista de que son procedimientos que producen información arqueológica y sólo pueden ser evaluadas en función de su adecuación a los propósitos para los cuales se utiliza (BATE, 1996, 158).

En este sentido, no podemos olvidar un hecho evidente sin el cual no podríamos conocer y explicar las sociedades del pasado: a pesar de que las evidencias arqueológicas son contemporáneas a nosotros y no se corresponden directamente con su situación en el pasado, la información empírica que podemos obtener de través de ellos tienen unas claras relaciones con los procesos desarrollados en el pasado y que pretendemos conocer. Las evidencias materiales reflejan patrones de comportamiento humano en el pasado, aunque el problema resida en saber discernir sobre qué restos materiales y atributos son relevantes al problema estudiado (Figura 4).

Para ello, en primer lugar es necesario realizar la caracterización de nuestros objetos de estudio a clasificar. En este caso concreto, los productos líticos manufacturados sobre distintos tipos de rocas.

Retomando el concepto ya señalado de contexto-momento, podremos establecer cómo se involucra el conjunto de artefactos y elementos que participan en las diversas actividades de una sociedad "viva". Los sujetos sociales realizan diversas actividades en las que se genera asociaciones de objetos que continuamente pueden ser cambiados tanto morfológicamente, como de lugar. En estas actividades, existen diversas asociaciones y disposiciones (distancia entre objetos, posiciones relativas) que son necesarias junto a otras que son causales. Asimismo existen materiales imprescindibles -y otros que no lo son tanto- para la realización de las tareas (LÓPEZ AGUILAR, 1990, 98). De este modo, un mismo espacio pudo haber sido empleado para realizar diversas actividades o una misma actividad durante un período de tiempo, generándose un proceso de acumulación y deposición. En cualquier caso, todas las actividades están social e históricamente determinadas y los materiales que participan en ellas presentan una carga de información concreta y precisa.

De las dos grandes clases de restos materiales que distinguía BINFORD (1964) -artefactos y elementos- nos interesa especialmente los primeros. Los artefactos, siguiendo a BINFORD (1964, 144) son entidades discretas, cuyas características formales no se alteran por la remoción de la matriz en la que se encontraban. Son transportables -en principio- y pueden ser analizados aunque no se disponga de información sobre su procedencia. Es decir, aunque se es consciente de que la pérdida de la información del contexto de donde proceden es un asunto irreparable, substancialmente mantienen buena parte de la misma, al ser objetos muebles y disponer de una información intrínseca. 


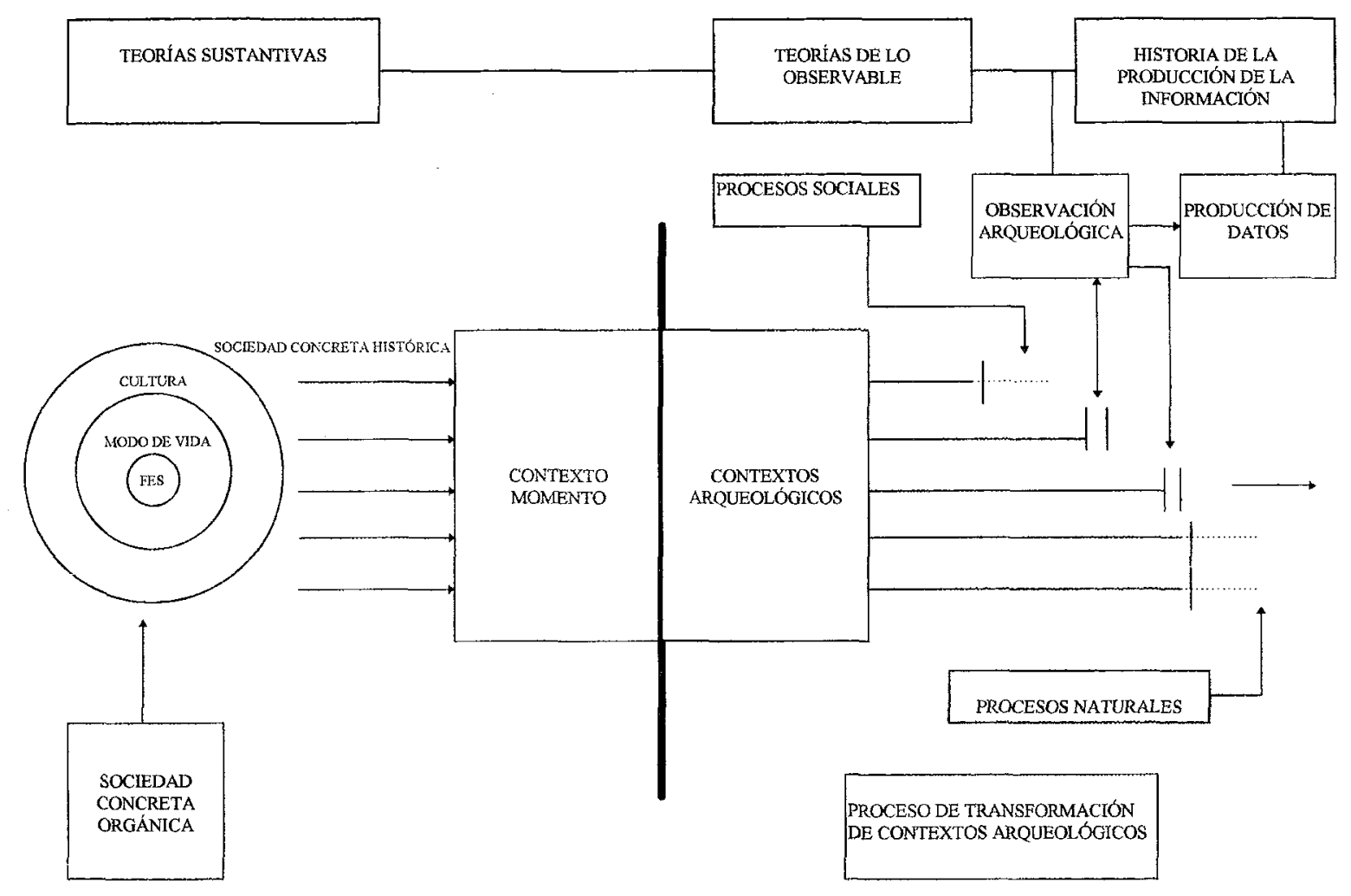

Figura 4: Esquema de la Historia de los contextos arqueológicos según F. López Aguilar (1990) y L. F. Bate (1998).

El problema reside en que en esta información intrínseca a cada artefacto, únicamente se establece la relación artefacto-rasgo, definiendo exclusivamente la tecnología en sí misma, y no la tecnología en el marco de la estructura económica -relaciones técnicas y sociales de producción-, que se pueden reconocer a través de la relación artefactos-coxtexto (RUIZ et alii, $1986,67)$. La relación artefacto-contexto, observable, fundamentalmente, en las unidades arqueológicas principales -áreas de actividad, unidades ocupacionales, asentamientos y territorios- y especialmente, sobre contextos de deposición primarios, es la que permite leer la conducta humana, analizar los procesos de trabajo y realizar la reconstrucción de los procesos socioeconómicos. La identificación de las áreas de actividad y su relación con las unidades habitacionales u ocupacionales permite la delimitación del valor de uso y de cambio de los productos, conocer cómo y quién los elabora y cómo y quién los utiliza. Mientras que cómo se distribuye y cómo se intercambian se podrá observar a través de las unidades mayores: unidades ocupacionales, asentamientos y territorios.

Es evidente que un análisis exclusivo de la relación artefacto-rasgo -procedimiento empleado habitualmente- nos permitirá clasificar y definir a los artefactos, reconocer el nivel tecnológico de cada yacimiento, las formas de consumo en algunos casos y el desarrollo técnico de la sociedad que los manufacturó (RUIZ et alii, $1986,67)$, pero estaremos ante un estudio de tecnología en sí misma, aislado de las relaciones sociales de producción que caracterizan a toda sociedad concreta.

En este sentido, además, sería interesante considerar a los productos especificando su función en relación con su espacio de deposición y la calidad de la información conservada en cada uno de los contextos arqueológicos, ya que es aquí donde podemos reconocer la estructura económica, siendo conscientes de algunas cuestiones que consideramos interesante destacar. En muchos casos, aunque conozcamos y documentemos perfectamente el contexto de los artefactos, y podamos hablar de productos domésticos, funerarios, de transporte, etcétera, aún así, es muy difícil establecer su funcionalidad. Por ejemplo, aunque documentemos la presencia de una lasca en un contexto o espacio de residencia y pensemos que ésta debió estar relacionada con alguna actividad doméstica, no podremos evaluar su función hasta que no se realicen estudios traceológicos. $\mathrm{O}$, al mismo tiempo, definir productos de carác- 
ter funerario es fácil si aparecen asociados a alguna sepultura, pero en ningún caso, podremos determinar si han sido manufacturados expresamente para tal ocasión o no. Del mismo modo, que la presencia en contextos arqueológicos de productos cuya funcionalidad pueda estar bien determinada, también contribuirá a la definición de áreas de actividad o del carácter de una determinada unidad o asentamiento. Por ello, creemos que es posible y se deben realizar clasificaciones en función del contexto -sin que el objetivo sea realizar una tipología-, pero ello no significa que se deban abandonar las realizadas a partir de la relación artefacto-rasgo, sino más bien, todo lo contrario, ambas deben estar articuladas de forma lógica.

En este sentido, un mismo producto, con similares rasgos -formales- puede ser documentado en diferentes contextos con diferentes contenidos -áreas de producción, áreas de consumo, almacenamiento, deposiciones funerarias, etc- y desde este punto de vista, si es interesante establecer y sintetizar la descripción de su configuración aparente, establecer su semejanza y diferencias con respecto a otros, observar su recurrencia, ya que en éstas, reside la expresión de la cultura (BATE,1978).

En resumen, consideramos que en la caracterización de los artefactos no sólo son importantes sus características intrínsecas -tecnológicas en sí- sino que también lo son más las relaciones que se pueden establecer, tanto con artefactos de la misma clase, como con los elementos y contextos en los que se puedan localizar -contenidos sociales-.

Ahora bien, el problema que se plantea, no solamente en el marco de esta investigación sino en todas las que se emprenden y que tienen relación directa con el análisis de materiales muebles, es que sólo tenemos acceso a una muestra de la población original, siendo, según las propiedades del contexto arqueológico del que proceda, un reflejo más o menos aproximado de las características de la misma y de los contextos sociales en los que participó. La muestra, además, se ha podido ver afectada por diversos procesos naturales o sociales que pueden llegar a modificar enormemente sus características e información. Es más, actualmente en muchas de las excavaciones o investigaciones que se emprenden se sigue considerando que la información contenida en los contextos arqueológicos no es problemática, realizando lecturas directas de los elementos y artefactos presentes. Se continúa sin considerar las características e historia de los depósitos arqueológi- cos, en especial, los procesos postdeposicionales que lo han podido alterar, al igual que se sigue otorgando el mismo grado de calidad de información arqueológica por el hecho de haber sido excavado en la actualidad o por el empleo de técnicas de registro muy rigurosas. De ahí, que cualquier análisis que realicemos debe partir de la evaluación de la calidad de la información contenida en los contextos arqueológicos, estableciendo una jerarquización de la misma y realizando una evaluación de la pertinencia de los mismos para la contrastación de las hipótesis planteadas.

Esta situación, nos permite evidenciar una situación muy preocupante. La realización de comparaciones de registros artefactuales procedentes de distintos contextos arqueológicos -o incluso de uno mismo- sin conocer sus historias deposicionales y de formación, debe tomarse con mucha precaución, al igual que se hace imprescindible adoptar una posición crítica con respecto a muchas de las secuencias regionales o a las seriaciones líticas de culturas o fases arqueológicas, ya que en buena medida, actualmente todavía no se ha realizado la evaluación de la calidad de los contextos arqueológicos que han servido de referencia en la elaboración las propuestas de seriación de la cultura material, ni tampoco las secuenciales.

Por todo ello, el análisis y clasificación de los artefactos líticos, en relación con sus componentes y contextos, debe estar encaminado a la determinación de los procesos de producción, distribución intercambio y consumo de forma concatenada, así como a valorar los procesos postdeposicionales que hayan podido alterar sus características. Así podremos reconocer cada uno de los procesos laborales relacionados con la producción lítica, los diferentes contextos en los que participó -áreas de actividad, yacimientos arqueológicos y territorios- y acercarnos a las características de las relaciones sociales establecidas en el marco de la producción de toda sociedad.

\section{BIBLIOGRAFÍA}

ANDERSON-GERFAUD, P.C., 1992: "Experimental cultivation, haverst and threshing of wild cereals and their relevance for interpreting the use of Epipaleolithic and Neolithic artefacts". Préhistoire de l'agriculture. Nouvelles approches expérimentales et ethnographiques. Monographie du CRA $n^{\circ}$ 6: 179-210. París.

ANDERSON-GERFAUD, P.C., 1993: " Interpretation of agricultural activities". Traces et fontion: les geste retrouvés. Colloque international de Liège. ERAUL, 50: 327-330. París. 
ANDERSON GERFAUD, P., MOSS, E. y PLISSON, H., 1987: "A quoi ont-ils servi?. L'apport de l'analyse fontionnelle". Bulletin de la Société Préhistorique Française, 84, 8:224-237. París.

BAENA, J. y LUQUE, M., 1990: "Modelo de análisis de industrias líticas no elaboradas". Xabiga, 6: 44-57. Jávea.

BARRERA, J.L., MARTÍNEZ, M.I., SAN NICOLAS, M. y VICENT, J.M., 1987: "El instrumental lítico pulimentado calcolítico de la comarca noroeste de Murcia: Algunas implicaciones socio-económicas del estudio estadístico de su petrología y morfología (I)". Trabajos de Prehistoria, 44: 87-146. Madrid.

BATE PETERSEN, L.F., 1978: Sociedad, formación social y cultura. Ediciones de Cultura Popular. México.

BATE PETERSEN, L.F., 1996: Una posición teórica en arqueología. Universidad de Sevilla. Tesis de Doctorado.

BATE PETERSEN, L.F., 1998: El proceso de investigación en arqueologia. Editorial Crítica. Barcelona.

BERNALDO DE QUIROS, F., CABRERA, V., CACHO, C. y VEGA, L.G., 1981: "Proyecto de análisis técnico para las industrias líticas". Trabajos de Prehistoria 38: 937. Madrid.

BEYRIES, S. (ed)., 1988: Industries lithiques. Tracéologie et Technologie. 2. vol. B.A.R. International Series 411 (I y II). Oxford.

BINDER, D. y PÉRLES, C., 1990: "Stratégies de gestion des outillages lithiques au néolithique". Paleo 2: 257283. París.

BINFORD, L.R., 1964: "A consideration of archaeological research design". American Antiquity, 29, 4:425-440.

BINFORD, L.R., 1977: For Theory building in archaeology. Academic Press. Nueva York.

BOEDA, E., 1992: "Le débitage discoïde et le débitage levallois récurrent centripète". Bulletin de la Société Préhistorique Francaise, 92: 392-404. París.

BOEDA, E., PELEGRIN, J., MEIGNEN, L., 1990: "Identification de chaines operatoires lithiques du Paleolithique Ancien et Moyen". Paleo, 2: 43-80. París.

BORDES, F., 1950: "Etude comparative des differentes techniques de taille du silex et des roches dures". L'Anthrpologie, 51: 1-29. París.

BORDES, F., 1961: Typologie du Paléolithique Ancien et Moyen. Cahiers du Quaternaire, 1. C.N.R.S. París.

BRADLEY, B.A., 1975: "Lithic reduction sequences: a glosary and discussion". Lithic technology. Making and using stone tools.: 5-13. La Haya.

CAHEN, D., 1984: "Technologie du débitage laminaire". Les fouilles de la place St-Lambert à Liège, 1. Liège, 18: 171-181. Lieja.

CAHEN, D., KEELEY, L.H., KARLIN, C., VAN NOTEN, F.L., 1980: "Méthodes d'analyse technique, spatiale et fonctionnelle d'ensembles lithiques". Helinium, 20: 209259.

CAHEN, D. y CASPAR, J.P., 1984: "Les traces d'utilisation des outils préhistoriques". L'Antropologie, $88, n^{\circ} 3$ : 277-308. París.

CARRIÓN, F., ALONSO, J.M., CASTILLA, J., CEPRÍAN, B y MARTÍNEZ, J.L., 1994: "Métodos para la identificación y caracterizaición de las fuentes de materias primas líticas prehistóricas". $1^{a}$ Reunión de Trabajo sobre aprovisionamiento de recursos líticos en Prehistoria. Valencia. Inédito.

CAUVIN, J., 1983: "Typologie et fonctions des outils préhistoriques: apports de la tracéologie a un vieux débat". Traces d'utilisation sur les outils néolothiques du Proche Orient. Travaux de la Maison de L'Orient, 5 (Lyon, 1982): 259-274. Lyon.
COGNÉ, J. y GIOT, P.R., 1952: "Étude petrographique des haches polies de Bretagne". Bulletin de la Société Préhistorique Française, 49: 388-395. París.

COLLINS, M.B., 1975: "Lithic tecnhnology as a means of processual inference". Lithic technology. Making and using stone tools.: 15-34. La Haya.

DEMARS, D.I., 1982: L'utilisation du silex au Paléolithique Supérieur: choix, approvisionnement, circulation. L'exemple du Bassin de Brive. Cahiers du Quaternaire, 5. CNRS. Paris.

DOMÉNECH FAUS, E.M., 1993: "La tecnología: un intento de aproximación al conocimiento del hombre prehistó. rico". Prehistoria en Alicante::31-32. Museo Arqueológico Provincial de Alicante. Alicante.

DUNNELL, R.C., 1978: Prehistoria moderna. Introducción sistemática a la Arqueología Prehistórica. Ediciones Istmo. Oviedo.

EDO, M., BLASCO, A. y VILLALBA, M.J., 1990: "Approche de la carte de distribution de la variscite des mines de Can Tintorer, Gavà (Catalonge) ". V th. International Flint Symposium. $n^{\circ} 17$. Bordeaux.

EDO, M. VILLALBA, M.J. y BLASCO, A., 1992: "Can Tintorer. Origen y distribución de minerales verdes en el Noroeste peninsular durante el Neolítico". Coloquio Aragón Litoral/Mediterráneo. Zaragoza.

EDO, M. VILLALBA, M.J. y BLASCO, A., 1995: "La calaíta en la Península Ibérica". $1^{\circ}$ Congreso de Arqueología Peninsular. Trabalhos de Antropología e Etnología, 35 (2): 127-155. Oporto.

FABREGAS VALCARCE, R., 1992: "Estudio funcional de útiles pulimentados: experimento de tala y análisis de microdesgastes". SPAL, 1: 107-123. Sevilla

GALLAGHER, J.P., 1977: "Contemporany stone tools in Ethiopia: implictions for archaeology". Journal of field Archaeology, 4: 407-414

GALLET, A. y TEXIER, P.J., 1991: "Caracterisation et evaluation des contraintes lors d'un débitage experimental de lames par pression. Perspectives expérimentales et implications archéologiques". La pierre prehistorique: 127-132. París.

GENESTE, J.M., 1991a: "Systèmes techniques de production lithique: Variations techno-économiques dans les processus de réalisation des outillages paléolothiques". Techniques et culture. 17-18: 1-35. Paris

GENESTE, J.M., 1991b: "L'approvisionement en matières premières dans les systemes de production lithique: la dimension spatiale de la technologie". Treballs d'arquelologia 1: 1-36. Barcelona.

GIOT, P.R., 1959: "Sur la réparatition, la mátiere et la morphologie des anneaux-disques". Bulletin de la Société Préhistorique Française, 55 (1-2): 45-48. París.

GOULD, R., 1978: Explorations in Ethnoarchaeology. University of Nuevo Mexico. Alburquerque.

GRACE, R., 1989: Interpreting the Function of Stone Tools. B.A.R. International Series, 474. 255 p. Oxford

HAYDEN, B., 1979: Paleolithic reflections. Lithic technology and etnograghic excavations among Australian Aborigenes. Camberra.

IBAÑEZ ESTÉVEZ, J.J. y GONZÁLEZ URQUIJO, J.E., 1994: Metodología de análisis funcional de instrumentos tallados en sílex. Universidad de Deusto. Bilbao.

JARDÓN GINER, P., 1990: "La metodología del análisis traceológico y su aplicación a conjuntos líticos prehis. tóricos". Saguntum, 23: 9-37. Valencia.

JOVER MAESTRE, F.J., 1997: Caracterización de las sociedades del II milenio ANE en el Levante de la Península lbérica: producción lítica, modos de trabajo, modo de vida y formación social. Tesis Doctoral. Universidad de Alicante. 
KARLIN, C., 1984: "Le débitage du silex à Pincevent, précedé de quelques notes de vocabulaire". Prehistoire de la pierre taillée. $2^{\circ}$ economie du débitage laminaire.: 39 44. París.

MARTÍNEZ, G. y AFONSO, J.A., 1994: «Sobre el concepto de la producción lítica". $f^{a}$ Reunión de Trabajo sobre aprovisionamiento de Recursos líticos en la Prehistoria. Valencia. (Inédito).

SCHIFFER, M. B., 1988: "¿Existe una premisa de Pompeya en arqueologia?". Boletín de antropologia americana, 18.: 5-32. México.

SCHIFFER, M.B., 1991: "Los procesos de formación del registro arqueológico". Boletín de Antropología Americana, 23: 39-46. México.

SEMENOV, S.A., 1981: Tecnologia Prehistórica. Estudio de las herramientas y objetos antiguos a través de las huellas de uso. Akal Editores. Madrid.

SIEVEKING, G. de G., CRADDOCK, P. T., HUGHES, M.J., BUSH, P. y FERGUSSON, J., 1970: "Characterization of prehistoric flint mine products". Nature, 228: 251 254.

SPAULDING, A. C., 1953: "Statistical techniques for the discovery of artifacts types". American Antiquity 18(4): 305-313.

TAKÁCS-BIRÓ, C., 1986: "Sources of raw materials used for the manufacture of chipped stone implements in Hungary". The scientific study of flint and chert.: 121 132.

TAVOSO, A., 1984: "Réflexions sur l'économie des matières premières au Moustetérien". Bulletin de la Société Préhistorique Française, (1(3): 79-82. París.

TIXIER, J., INIZAN, M.L., ROCHE, H., 1980: Prèhistoire de la pierre taillée. Terminologie et technologie. París.

TERRADAS, X, PLANA, F. y CHINCHÓN, J.S., 1991: "Aplicación de técnicas analíticas para el estudio de las materias primas líticas prehistóricas". Arqueología. Nuevas tendencias: 141-167. Barcelona.

TORRENCE, R., 1989: Time, energy and stone tools. Cambridge University Press.

TORTI, C., 1983: "Contribution à l'étude paléogéographique du Massif au Paléolithique Moyen et Supérieur". Bulletin de la Société Préhistorique Française, 80(10-12): 300 307. París.

TRIGHAM, R., COOPER, G., ODELL, G.H., VOYTEK, B. y WHITMAN, A., 1974: "Experimentation in the formation of edge-damage: a new approach to lithic analysis". Journal of Field Archaeology, 1: 171-196.
TSCHAUNER, H.W.W., 1985: "La tipología: Herramienta u obstáculo?". La clasificación de artefactos". Boletín de antropología americana, 12: 39-74. México.

UNGER-HAMILTON, R., 1983: "An investigation into the variables affesting the development and the appearence of plant polish on flint blades". Traces d'utilisation sur outils néolithiques du Proche Orient. Travaux de la Masson de l'Orient, 5 (Lyon, 1982): 243-250. Lyon.

UNGER-HAMILTON, R., 1985: "Microscopic striations on flint sickle-blades as an indication of plant cultivation: preliminary results". World Archaeology, 17: 121-126.

UNGER-HAMILTON, R., 1988: Method in microwear analysis. Prehistoric sickles and other tools from Arjoune, Siria. B.A.R. International Series, 435. 331 p. Oxford.

UNGER-HAMITON, R., 1989: "Analyse expérimentale des microtraces d'usure: quelques controverses actuelles". L'Anthropologie, 93, 3: 659-672. París.

VARGAS, I., 1990: Arqueologia, ciencia y sociedad. Caracas.

VAUGHAN, P. y PLISSON, H., 1984: "Comment presenter les données tracéologiques?". Early Man News, 9/10/ 11. Part $Y$ :: 177-182. Tübingen.

VELOZ MAGGIOLO, M., 1984: "La arqueología de la vida cotidiana". Hacia una Arqueología Social. Actas del $1^{\circ}$ simposio de la Fundación de Arqueología del Caribe:: 92-113. San José. Costa Rica.

VELOZ MAGGIOLO, M., 1984: "La arqueología de la vida cotidiana: matices, historia y diferencias". Boletín de Antropología Americana, 10: 5-22. México.

VILLA, P., 1982: "Conjoinable pieces and site formation processes". American Antiquity, 47, 2: 26-290

WARD, G.K., 1974: "A sistematic approach to the definition of sources fo raw material". Archaeometry, 16 (1): 41-53.

WATSON, P.J., LEBLANC, S.A. y REDMAN, C.L., 1971: El método cientifico en arqueologia. Alizanza Editorial. Madrid.

WHEAT, J.B., GIFFORD, J.C., y WASLEY, W.W., 1958 "Ceramic variety, type cluster, and ceramic system in Southwetern pottery analysis". American Antiquity, 24(1): 34-47. 